\title{
DESAFIOS E CONFLITOS ÉTICOS VIVENCIADOS PELA EQUIPE DE ENFERMAGEM COM PACIENTE EM PROCESSO DE MORTE E MORRER
}

Challenges and Ethical Conflicts experienced by nursing staff with patient in the process of death and dying

Darliz Justino Huber ${ }^{1}$, Maria Salete Salvaro², Izabel Scarabelot Medeiros ${ }^{2}$, Maria Tereza Soratto ${ }^{\star}$

${ }^{1}$ Enfermeira. Universidade do Extremo Sul de Santa Catarinense, Criciúma, SC.

${ }^{2}$ Enfermeira. Mestre em Educação. Professora do Curso de Enfermagem. Universidade do Extremo Sul de Santa Catarina - Criciúma - SC.

\section{Endereço para correspondência:}

${ }^{*}$ Maria Tereza Soratto

Departamento de Enfermagem - Unidade Acadêmica da Saúde - UNASAU UNESC.

Av. Universitária, 1105. Criciúma - SC - Bairro Universitário.

CEP - 88806-000

Email: guiga@unesc.net 


\section{Resumo}

Estudo com objetivo de analisar os desafios e conflitos éticos vivenciados pela equipe de enfermagem frente ao paciente em processo de morte e morrer de uma Clínica Médica Feminina, de um Hospital de grande porte de um município do Extremo Sul Catarinense. Pesquisa de abordagem qualitativa, descritiva e de campo. Aplicou-se entrevista semiestruturada com 08 profissionais da equipe de enfermagem. A análise dos dados foi realizada a partir da análise de conteúdo. A família foi considerada o maior desafio enfrentado pela equipe de enfermagem, seja estar diante da dor do familiar; as dificuldades inerentes à comunicação da má notícia; não poder realizar alguns procedimentos solicitados pelos familiares e falta de atenção de alguns familiares. Outros conflitos delineados na pesquisa relacionaram-se ao saber lidar com o processo de morte e morrer; atendimento tardio; falta de material e os conflitos éticos e bioéticos que envolvem a reanimação cardiovascular em cuidado paliativo. A atuação da Equipe de Enfermagem frente à família e paciente durante o processo de Morte e Morrer deve ser embasada na solidariedade, empatia, apoio, carinho, dedicação, amor; com uma comunicação clara e respeitando os princípios éticos que norteiam o cuidado de enfermagem, além da assistência técnica, sendo essencial oferecer apoio e consolo aos familiares.

Palavras-chave: ética; equipe de enfermagem; morte; tanatologia.

\section{Abstract}

Study to analyse the challenges and ethical conflicts experienced by nursing staff in front of the patient in the process of death and dying from a medical clinic, a large Hospital of a city in the extreme south of Santa Catarina. Qualitative, descriptive research and field. Applied semi-structured interview with professional nursing team 08. Data analysis was carried out from the analysis of content. The family was considered the greatest challenge faced by nursing staff, whether it be on familiar pain; the difficulties inherent in the communication from the bad news; not being able to perform some procedures requested by families and lack of attention to some relatives. Other conflicts outlined in research related to dealing with the process of death and dying; late service; lack of material and ethical and bioethical conflicts which involve the reanimation cardio-vascular in palliative care. The performance of nursing staff in front of the family and patient during the process of death and dying should be based on solidarity, empathy, support, caring, dedication, love; with clear communication and respecting ethical principles that guide nursing care, in addition to the technical assistance being essential to offer support and comfort to the families.

Keywords: ethics; nursing, team; death; thanatology. 


\section{INTRODUÇÃO}

A morte é um fato inevitável, inerente ao ciclo dos seres humanos relacionado ao nascer, crescer e morrer ${ }^{1}$. A morte e o morrer mesmo parecendo termos iguais possuem significados diferentes. A morte significa o fim da pessoa humana no seu processo histórico, o seu corpo concreto. Morrer, pelo contrário, é a fase que a pessoa enfrenta em sua última fase de transição entre vida para a morte. $\mathrm{Na}$ sociedade contemporânea cada vez mais a morte acontece em ambientes hospitalares, situação que pode gerar situações de conflito, desafios e dilemas, tanto para a família como para a equipe de saúde, em especial ao enfermeiro, profissional que atua diretamente com ambos ${ }^{2}$.

A morte ocorre no cotidiano daqueles que escolheram como ofício a arte de cuidar, de maneira silenciosa, no contato mais íntimo dos profissionais com os que estão morrendo ${ }^{3}$. No ciclo de vida humano a morte é uma etapa a ser cumprida pelo ser humano, sendo que o tema morte é um assunto de difícil abordagem. A equipe de enfermagem deve dar atenção especial ao tema, tanto na perspectiva da formação acadêmica como na atuação profissional ${ }^{4}$.

Diante disso, este trabalho oferece subsídios para o entendimento de que o cuidado de enfermagem no processo de morte e morrer do paciente necessita de preparo adequado da equipe de enfermagem tanto no âmbito técnico, como na perspectiva emocional e espiritual ${ }^{4}$.

O conhecimento sobre tanatologia pode subsidiar a reflexão sobre 0 processo de morte e do morrer, possibilitando o cuidado qualificado ao paciente na terminalidade e à família ${ }^{5}$. A equipe multiprofissional deve buscar um cuidado humanizado e qualificado, tanto para o paciente como para a família, refletindo sobre suas práticas cotidianas, para que se tornem mais conscientes da filosofia dos cuidados paliativos, assim como dos desafios éticos a serem enfrentados.

A negação da morte é perceptível em todos os setores da sociedade, até mesmo entre os profissionais de saúde, que evitam falar sobre este evento. Em sua linguagem do dia a dia, referem-se à mesma como óbito, dando a impressão de ser uma palavra mais sutil e menos agressiva, mas que não muda em nada os 
sentimentos perante à finitude ${ }^{6}$.

A morte, num contexto mais moderno, é vista como um processo, como um fenômeno progressivo e não mais como um momento. Sabe-se que assistir o paciente nestas horas é difícil, pois origina sensação de tristeza, frustração, impotência e até mesmo culpa por falhas na assistência prestada, dando a sensação de que tudo que foi feito não foi o bastante, que poderia ter sido feito sempre mais e melhor. Além disso, os conhecimentos existentes na prática da enfermagem, como na área de saúde em geral, visam à recuperação e a preservação da saúde, e quando há a possibilidade da morte, o profissional reage emocionalmente, chegando ao sofrimento, ao se deparar com a fragilidade, vulnerabilidade, mortalidade e as limitações do ser humano².

Assim, mesmo nos hospitais, onde aparelhos de alta tecnologia são utilizados para manter os organismos do paciente em funcionamento e profissionais são treinados para manipulá-los, o preparo emocional para assistir às necessidades reais do paciente que está morrendo e sua família muitas vezes não é adequado. $\mathrm{Na}$ verdade, a tecnologia prolonga a vida dos pacientes, mas não ajuda no processo de morrer, sendo da equipe que o assiste essa responsabilidade ${ }^{2}$.

Devido ao contexto que envolve o processo de morte e morrer e toda sua complexidade, os profissionais da equipe de enfermagem tornam-se alvo de constantes desafios e conflitos éticos. Um desafio ou problema ético na área de saúde pode ser definido como uma dificuldade na tomada de decisões em relação a uma pessoa (o paciente), cuja resolução é necessária, mas que deve levar em conta valores ou princípios que especificam o que deve ser feito ${ }^{2}$. Desse modo, a ética refere-se aos padrões de conduta moral, significa saber o que é certo e o que é errado, e como agir para chegar ao equilíbrio ou ao bom senso 4 .

A morte, no cotidiano da enfermagem, está sempre presente e esses profissionais que convivem diariamente com o processo morte e morrer possuem dificuldades para enfrentá-lo, preferindo, na maioria dos casos, evitar o envolvimento com o paciente e sua família, a fim de preservar sua saúde psíquica. Frente a isso, verificando-se que existem dificuldades, conflitos e desafios enfrentados pelo pessoal da enfermagem no processo de morte e morrer, este trabalho busca fornecer uma contribuição para o entendimento de tais conflitos, bem como de formas de se atuar perante os mesmos. 
Considera-se que a equipe de enfermagem pode enfrentar conflitos que permeiam o processo de morte/morrer, tais como: não revelação do diagnóstico ao paciente; não-aceitação do processo de morte e morrer pela família; conflitos relacionados à ordem de não ressuscitar (ONR); falta de sensibilização da equipe frente ao processo de morte, quando o cuidado engloba higiene, conforto, controle da dor, mas não ocorre a cura. Pesquisa com objetivo de conhecer os desafios e conflitos éticos vivenciados pela equipe de enfermagem frente ao paciente em processo de morte e morrer de uma Clínica Médica Feminina, de um Hospital de grande porte de um município do Extremo Sul Catarinense.

\section{MATERIAL E MÉTODOS}

Pesquisa de abordagem qualitativa, descritiva e de campo. $O$ estudo desenvolveu-se em um hospital de grande porte do Extremo Sul de Santa Catarina. Aplicou-se entrevista semiestruturada com 08 profissionais da equipe de enfermagem da Clinica Médica. Utilizaram-se como critérios de inclusão: profissionais de Enfermagem atuantes na Clínica Médica; período vespertino e período noturno; tempo de atuação mínimo de 3 meses; como critérios de exclusão considerou-se os profissionais que atuam no período matutino; profissionais de férias ou afastamento do trabalho durante o processo de pesquisa.

A entrevista semiestruturada foi realizada por uma das pesquisadoras, ocorrendo no horário de trabalho, com a duração de cerca de 30 a 40 minutos; em ambiente privado para garantir a privacidade das informações e o bem estar do entrevistado. Em relação à amostra da pesquisa de 17 profissionais da equipe de enfermagem, aceitaram participar da mesma somente 08 profissionais, talvez em virtude da temática que ainda é permeada por medo e aversão. A transcrição das entrevistas foi realizada por uma das pesquisadoras na íntegra.

Os questionamentos da entrevista levantaram a caracterização do perfil dos profissionais; capacitação da equipe de enfermagem; definição de morte e o processo de morte-morrer; os sentimentos da equipe de enfermagem; a atuação da equipe frente o processo de morte; a identificação das cinco fases de Kubler Ross; capacidade para lidar com a morte; os desafios vivenciados e o enfrentamento da equipe de enfermagem nos cuidados à pessoa no processo de morte e morrer; proposta da equipe de enfermagem. 
A análise e interpretação dos dados qualitativos foram realizadas pela análise de conteúdo, a partir da categorização dos dados. Categoria refere-se a um conceito que abrange elementos ou aspectos com características comuns ou que se relacionam entre si, são estabelecidas para classificar os eventos. Categorizar é agrupar elementos, ideias ou expressões em torno de um conceito ${ }^{7,8}$.

Dentre os aspectos éticos o consentimento livre e esclarecido prevê a anuência do sujeito da pesquisa após a explicação completa sobre a natureza da mesma, seus objetivos, métodos, benefícios previstos e potenciais riscos que possam acarretar, formulada em termo de consentimento, autorizando sua participação na pesquisa. Na pesquisa utilizou-se um termo de consentimento livre e esclarecido, informando aos participantes os objetivos, métodos, direito de desistir da mesma e sigilo em relação à pesquisa. Para preservar o sigilo decorrente das entrevistas realizadas, de acordo com as diretrizes e normas regulamentadoras que envolvem pesquisa com Seres Humanos e Grupos Vulneráveis da Resolução 510/2016 ${ }^{9}$, utilizou-se a letra "E" para os Enfermeiros e a letra "T" para os Técnicos de Enfermagem; seguido do respectivo número - E1 a E2; T1 a T6. A pesquisa foi aprovada pelo Comitê de Ética em Pesquisa da UNESC pelo Projeto no 1.444.490/2016.

\section{RESULTADOS E DISCUSSÃO}

\section{Caracterização do perfil dos profissionais}

Em relação ao perfil $87,5 \%$ dos profissionais é do sexo feminino e $12,5 \%$ do sexo masculino, havendo, desse modo, predominância do sexo feminino na amostra. Em relação à formação $75 \%$ dos profissionais são técnicos de enfermagem e $25 \%$ enfermeiros. A idade dos profissionais variou entre 18 a 45 anos. O tempo de atuação na enfermagem variou de 3 meses à 22 anos, sendo que o tempo de atuação na instituição variou de 5 meses à 22 anos. O turno de trabalho prevalecente é o vespertino, no qual atuam $50 \%$ dos profissionais, enquanto 0 restante distribui-se em $25 \%$ em turno misto e $25 \%$ com jornada de trabalho noturno.

\section{Capacitação da Equipe de Enfermagem para lidar com o processo de morte morrer no cotidiano de seu trabalho}

Em relação à capacitação da equipe de enfermagem para lidar com o 
Artigo Original

Atenção à Saúde

processo de morte-morrer no cotidiano do trabalho a maioria da equipe não recebeu capacitação relacionado à tanatologia(E2; T1; T2; T3; T4). O enfermeiro E1 relatou ter recebido capacitação na temática na educação continuada e o técnico de enfermagem T6 recebeu capacitação abordando os aspectos técnicos. O técnico T5 relatou a importância do preparo do profissional para lidar com o processo de morte e morrer tanto no aspecto técnico como humano.

T5 - "Sim, temos que saber lidar com todos os processos de preparar o corpo para o necrotério, lidar com a dor dos familiares e entender que faz parte do processo da vida partir dessa para a melhor".

Vislumbra-se a importância do entendimento dos profissionais sobre o processo de morrer, buscando a humanização do cuidado ${ }^{5}$. Azeredo, Rocha, Carvalho $^{10}$ ressaltam o sentimento de frustração e incapacidade dos acadêmicos quando deparam-se com a morte. Existe a necessidade de preparo acadêmico sobre tanatologia, com abordagem do tema sobre a morte e o morrer na grade curricular da graduação possibilitando aos estudantes que atuem no campo de estágio e na vida profissional com um melhor preparo para o enfrentamento da morte ${ }^{5,10}$.

Dessa forma, considera-se imprescindível que a equipe de enfermagem tenha capacitação voltada à tanatologia, tanto abordando os aspectos técnicos, quanto os aspectos éticos e humanos, para lidar adequadamente com o paciente em processo de morte e morrer e com a família.

\section{Definição de morte e o processo de morte-morrer}

A concepção de morte perpassa a definição biologicista; sendo um processo natural associado à terminalidade; passagem que pode envolver um processo de perda, sofrimento e desgaste; necessitando do cuidado humanizado de enfermagem e proporcionado uma morte sem dor. A definição biologista da morte é citada nas falas dos técnicos de enfermagem T3 e T5, a concepção de ser uma passagem é definida pelo técnico T5:

T3 - “"É a ausência de sinais vitais, e o processo de morte/morrer é o paciente em fase terminal"." 
T5 - " "Quando todas as nossas células param de receber oxigênio, nosso coração para de bombear. Para mim, é um processo, apenas uma passagem, digamos assim, para irmos para outra vida e para o mundo espiritual"."

A irreversibilidade do processo foi citado pelo técnico T6; permeado pelo sofrimento e desgaste tanto do paciente como da família(E2):

E2 - "Morte é o processo da perda de um ente querido; morte e morrer é o processo anterior, que envolve muito sofrimento e desgaste ao paciente $e$ familiares".

T6 - "É quando o paciente encontra-se em fase terminal, quase indo a óbito, sendo este muitas vezes irreversível".

$\mathrm{Na}$ definição de morte os técnicos de enfermagem T1; T2 e T4 relacionaram o processo de morte e morrer a necessidade do cuidado humanizado, com conforto e procedimentos técnicos necessários ao paciente.

T1 - "Manter cuidados necessários, carinho, atenção com todos, técnicas necessárias, éticas dignas, realizar procedimentos corretos com ética, carinho com familiares e procedimentos cabíveis".

T2 - "Seguir medidas de conforto, respeito ao óbito".

T4 - "Morte é quando não tem mais nada que se possa fazer para o paciente, é o processo de morte-morrer, é quando o paciente está no estágio, e nós temos que proporcionar um conforto dos pacientes e familiares para uma morte mais digna".

O enfermeiro E1 ressaltou que a morte é um processo natural, que demanda o controle da dor por parte da equipe de cuidados: E1 - "Um processo natural, entretanto, nós da enfermagem somos encarregados de tornar este processo menos doloroso possível".

A morte suscita várias abordagens que depende de fatores religiosos, sociais e culturais, podendo ser definida como a perda de fluidos vitais, a separação 
da alma, a perda irreversível da capacidade de consciência e integração social ${ }^{11}$. Em artigo de revisão de Nunes; Araújo; Silva ${ }^{1}$ os profissionais consideram o processo de morte-morrer como um ciclo natural da vida.

Conforme Mendes $^{12}$, ao admitir que se esgotaram as possibilidades de cura do paciente, os enfermeiros mostram em suas falas a necessidade de serem realizados os cuidados paliativos, mas com conforto e cuidado humanizado, a fim de que este não sofra durante o processo de morte. No campo dos cuidados paliativos existem práticas e estudos que objetivam o resgate da dignidade do paciente, respeitando a sua autonomia, a fim de evitar que ocorra uma obstinação terapêutica. Compreende-se que a aproximação ao sentido que a etapa terminal da vida traz aos profissionais que se ocupam dela, é uma ferramenta para permitir que a equipe de saúde tenha uma aproximação melhor com o paciente.

Quando a morte está próxima e não há mais nada a fazer, encontra-se a enfermagem do cuidado e acolhimento, que se faz presente no sofrimento, na dor, na despedida, sendo suporte e elo de comunicação entre o paciente e família.

\section{Os sentimentos da Equipe de Enfermagem em relação ao processo de morte- morrer do paciente}

Os profissionais de enfermagem vivenciam diversos pesares frente a assistência aos pacientes em situação de fim de vida ${ }^{13}$. Os sentimentos da equipe de enfermagem frente ao processo de morte e morrer esta associada à tristeza, dor, consternação; apego; descanso para o sofrimento; sendo necessário o desapego, a empatia, o cuidado e a compaixão em relação ao paciente e família.

Os sentimentos mais evidentes frente ao processo de morte e morrer expressos pela equipe de enfermagem foram à tristeza, dor, empatia e consternação. A morte representa um processo de finalização o que determina sentimentos de perda e pesar, por vezes misturado à compaixão e humanização do cuidado.

E1 - "Empatia, tristeza".

E2 - "Ver a dor da família vivenciando a morte: doação, carinho, atenção e apego".

T1 - "Faz parte da profissão, mas me deixa triste, mas faço o possível 
para não levá-los para casa e tento fazer o melhor por estes pacientes".

T2 - "Consternação".

T4 - "Compaixão ao próximo que está passando por este processo".

T6 - "Sempre dá uma tristeza, pelo paciente e pelos familiares".

Em pesquisa de revisão de Nunes; Araújo; Silva ${ }^{1}$ em relação à morte do paciente a equipe de enfermagem descreveu sentimentos de pesar, dor, tristeza, impotência, angústia e sofrimento. $O$ estudo de Freitas et al ${ }^{5}$ identificou o sofrimento da equipe de enfermagem perante o processo de morte e morrer, com sentimentos de dor pela perda, sentimentos de negação, insatisfação, tristeza, raiva e impotência.

A morte pode ser um descanso para o sofrimento, o que necessita do desapego da familia, do paciente e da equipe envolvida no cuidado:

T3 - "Dependendo da fase em que o paciente se encontra (sofrendo), eu dou graças a Deus, pois só assim a família também sofrendo com a situação fica descansada, apesar da tristeza".

T5 - "Processo da morte é algo inevitável que um dia todos nós teremos que passar. Por isso, é algo necessário que aconteça. Eu acho que muitas vezes somos egoístas e não querermos que aquele nosso amigo ou parente morra, mas muitas vezes devido à patologia dele, está sofrendo muito, é melhor partir".

Para Fontoura ${ }^{14}$ a tristeza é natural e, embora alguns interpretem os sinais de compaixão e envolvimento sadio como indicações de envolvimento excessivo, o enfermeiro cujos olhos se enchem de lágrimas em um momento sensível transmite um sentimento de empatia, não de perda de controle, aliás, necessita-se aprender a demonstrar confortavelmente a preocupação e a compaixão que são parte de nossa constituição emocional.

$O$ sentimento expressado pela equipe de enfermagem relaciona-se a aproximação constante no cuidado ao paciente e família'. A presença em todo o processo de morte e morrer e na passagem da vida podem representar compaixão pelo ser humano nas horas finais e empatia com o paciente e família, não representando perda de controle por parte da equipe de enfermagem e sim o fato dos profissionais serem humanos. 


\section{O enfrentamento do processo de morte e morrer pela Equipe de Enfermagem}

O processo de morte e morrer é enfrentado pela equipe de enfermagem como um processo natural, apesar do sofrimento, tristeza e muitas vezes o apego, segundo os relatos dos profissionais

T3 - "Enfrento naturalmente apesar de ficar triste, pois a vida continua e temos que atender os que virão pela frente."

T5 - "De forma natural, porém quando me apego um pouco ao paciente, fico um pouco triste."

T6 - "Tento encarar de forma natural, pois se me apegar muito não dá para trabalhar."

A experiência adquirida com o processo de morte do paciente possibilita uma postura calma do profissional e a humanização do cuidado ao paciente e à família, segundo o relato da Enfermeira: E1 - "Aprendi a adquirir experiência e a manter a calma, ser humana e lembrar que por trás do paciente há quase sempre familiares".

O Técnico de Enfermagem T4 ressaltou a importância da troca de conhecimento com os profissionais para o enfrentamento do processo de morte e morrer: T4 - "Procurando pessoas que tenham mais experiência nesse processo para poder me auxiliar".

O trabalho em equipe no processo de morte e morrer promove meios de melhor lidar com o sofrimento humano, sendo essencial compartilhar as experiências entre os profissionais e a integração da equipe multidisciplinar ${ }^{13}$.

O cuidado do profissional para não envolver-se emocionalmente e oferecer apoio e consolo aos familiares foi citado pelo enfermeiro E2 como forma de enfrentar o processo de morte e morrer no cotidiano do cuidado: E2 - "Temos que nos controlar para não se envolver psicologicamente e saber as coisas, sabendo dar apoio e consolo aos familiares".

O relato do profissional de manter-se afastado do paciente em processo 


\section{Atenção à Saúde}

de morte e morrer é considerado um mecanismo de defesa na tentativa de se proteger. O distanciamento é uma forma de prevenir o sofrimento emocional, evitando assim o envolvimento afetivo com o paciente, o que pode interferir na assistência humanizada na terminalidade'.

A importância do equilíbrio emocional para lidar com o processo de morte foi citado pelo técnico de enfermagem: T2 - "Tendo em vista os vários casos que já vivenciei, procuro me manter equilibrado emocionalmente".

A fé é considerada baluarte para o enfrentamento de perdas na profissão nas palavras do técnico de enferamgem: T1 - "Com muita força de vontade, tenho harmonia com a equipe, sempre com ajuda divina, Deus, se estamos nessa profissão é porque Deus nos colocou aqui.".

Pesquisa de Nunes; Araújo; Silva ${ }^{1}$ demonstra que os profissionais encontram na espiritualidade o apoio emocional para o enfrentamento do processo de morte e morrer dos pacientes, a morte na concepção espiritual pode transformarse em alivio da dor e paz para o sofrimento. A espiritualidade atua como um suporte emocional e contribui para aceitação da morte, aliviando o sofrimento dos pacientes e amenizando a dor causada pela perda e contato com da morte ${ }^{1}$.

A concepção social de morte é resultado de um longo processo histórico, marcado por diferentes sistemas econômicos e sociais, bem como por costumes que envolvem dimensões existenciais, subjetivas e espirituais ${ }^{11,15}$. A morte faz parte do desenvolvimento humano acompanhando-o em todo o seu ciclo vital e deixando suas marcas ${ }^{1,16}$. A sociedade é propensa a evitar e ignorar a morte ${ }^{17}$.

O processo de morte e morrer é algo natural e como tal deve ser enfrentado no cotidiano do processo de trabalho da enfermagem. A experiência para lidar com a morte é essencial para o profissional saber consolar tanto o paciente como a família e ser suporte nas horas de maior dor e desespero. A fé em algo superior e a percepção de que a morte não é o fim de tudo, o dom do cuidado que faz da profissão de enfermagem ser humanizada é essencial para o enfrentamento do processo de morte pela equipe de enfermagem.

\section{A atuação da Equipe de Enfermagem frente à família e paciente durante o processo de Morte e Morrer}


A atuação da Equipe de Enfermagem frente à família e paciente durante 0 processo de Morte e Morrer deve ser embasada na solidariedade, empatia, apoio, carinho, dedicação, amor; com uma comunicação clara e respeitando os princípios éticos que norteiam o cuidado de enfermagem, além da assistência técnica; segundo a equipe de enfermagem.

E1 - "Demonstro empatia, solidariedade e no momento e expressar as informações tento ser branda e clara (compreensível).".

E2 - "Dando apoio e carinho, a eles é o que posso oferecer".

$T 1$ - "Com educação, ética, ajudando no quer for necessário, orientando sempre nos procedimentos cabíveis, com carinho e dedicação".

T2 - "Tecnicamente, calmo, é necessário".

T3 - "Procuro entender o sofrimento do paciente e familiares, procedendo com amor e respeito".

T4 - "Orientando e respeitando os sentimentos dos familiares, oferecendo conforto e alivio da dor aos pacientes".

T5 - "De forma natural".

T6 - "Com solidariedade e respeito à pessoa".

Kübler - Ross ${ }^{17}$ em seu clássico livro sobre a Morte e o Morrer destaca a necessidade de reflexão contínua da equipe de saúde sobre suas práticas de cuidado, sendo importante o conhecimento do contexto em que vivem os pacientes e familiares. No momento difícil da terminalidade, a presença da família e da equipe é primordial para o enfrentamento do processo de morte e morrer. A partir do cuidado digno, o paciente se sentirá mais seguro para vivenciar a travessia ${ }^{13}$.

O tratamento interdisciplinar evita a fragmentação do cuidado, sendo importante a humanização do cuidar do paciente em fase terminal com respeito à autonomia do paciente e sua família, a coparticipação e a construção de projetos terapêuticos consensuais que visem dar mais vida aos anos, que anos à vida ${ }^{17}$.

\section{A identificação das cinco fases do processo de morrer nos pacientes}

As 5 fases da morte identificadas por Kubler Ross ${ }^{17}$, são delineadas pela negação, raiva e ira, barganha, depressão e aceitação. A maioria dos profissionais 
identificou algumas destas fases na assistência de enfermagem ao paciente no processo de terminalidade.

E1 - "Negação, ira e raiva, barganha, depressão, aceitação."

T1 - "Algumas pessoas são revoltadas, outras aceitam com muita fé de melhorar, quando ficam muitos dias internados desanimam, ficam tristes, algumas pessoas têm bastante fé, acabam desanimando, quando estão em fase terminal, muita tristeza, desânimo, não se alimentam mais, temos certeza que não tem vontade de viver.".

T2 - "Negação, revolta, desânimo e perda de fé.".

T3 - "1) Eles ficam revoltados, 2) não aceitam a situação, 3) procuram se apegar a uma religião para aumentar a fé, 4) ficam deprimidas, 5)aceitam a situação.".

T5 - "[...] decepção, quando o paciente se deprime, não aceita, pede ajuda a Deus, porém outros pacientes aceitam.".

Os profissionais T4; T6 e E2 não souberam identificar as fases do processo de morte-morrer descritas por Kübler-Ross.

O processo de morte e morrer percorre vários estágios, segundo Kübler Ross $^{13}$. A primeira fase constitui-se pela negação e isolamento, que geralmente vem com o diagnóstico, o paciente procura provar de todas as formas que houve um engano, necessitando de tempo para absorção da ideia ${ }^{17}$.

No segundo estágio, confirmado o diagnóstico, a raiva por interromper seus planos e a própria vida se mescla ao ressentimento e à inveja daqueles que estão saudáveis. A equipe precisa, por meio da empatia, entender esse período e contornar situações que fazem parte do choque pela nova condição e do processo em curso, sendo comum que os profissionais evitem os pacientes nesta fase ${ }^{17}$.

No terceiro estágio, o da barganha, há uma tentativa de adiar a morte como um prêmio por bom comportamento. Há promessas de novas atitudes e de mudanças de estilo de vida, na esperança de prolongar um pouco mais a sobrevivência. Arrependimentos por situações concretas ou fantasiosas vividas como pecados fazem que o adoecimento seja sentido como castigo pelo doente ${ }^{17}$.

O quarto estágio, a depressão que decorre não somente do impacto da 
Artigo Original

Atenção à Saúde

doença sobre o indivíduo, mas sobre a família e as dificuldades financeiras, a necessidade de o outro cônjuge trabalhar e o afastamento dos filhos, que por vezes precisam ficar aos cuidados de parentes ${ }^{17}$.

O último estágio, de aceitação, coincide com o período de maior desgaste físico, parece ser mais difícil viver do que morrer e os sentimentos desvanecem. É um período em que o paciente pode querer falar sobre seus sentimentos, mas precisa que haja pessoas disponíveis e preparadas internamente para esse contato $^{17}$.

Pode haver uma sobreposição dos 5 estágios, sendo que em todos eles, mesmo para os pacientes mais realistas, há sempre uma ponta de esperança que não deve ser retirada com verdades cruéis ditas de forma direta ${ }^{17}$.

Capacidade para lidar com o processo de morte-morrer no cotidiano do trabalho

Quando se questionou os profissionais sobre a capacidade de lidar com o processo de morte-morrer no cotidiano do trabalho, a maioria considerou que sim (E1; E2; T1; T3; T5; T6); somente os profissionais T2 e T4 consideram as dificuldades inerentes neste processo, sendo necessário melhor preparo da equipe de enfermagem (T4).

O profissional que não recebeu capacitação adequada sobre terminalidade possui maior dificuldade em lidar com o paciente no processo de morte e morrer e seus familiares durante a assistência de enfermagem e na comunicação de más notícias ${ }^{1,5}$.

Existe deficiência na formação dos profissionais que lidam com a morte e o luto, principalmente naqueles que trabalham em contextos de saúde ${ }^{1,3,13,15}$. Desta forma surge a necessidade de formação dos profissionais da saúde em educação para a morte ${ }^{1,3,13,15,18-21}$.

\section{Os maiores desafios e conflitos vivenciados pela Equipe de Enfermagem nos cuidados à pessoa no processo de morte e morrer}

A familia foi citada como um dos maiores desafios enfrentados pela equipe de enfermagem, seja estar diante da dor do familiar (E2; T5; T6), as dificuldades inerentes à comunicação da má notícia(T4); não poder realizar alguns 
procedimentos solicitados pelos familiares (T3; T4), falta de atenção de alguns familiares (T1).

E2 - "Desafio de saber lidar com a situação que não e fácil, envolve muita dor, sentimento, família e paciência de resolver a situação".

T5 - "Apenas a dor dos familiares".

T6 - "Quando estou diante de um familiar".

T4 - "Um dos maiores desafios nesse processo é o de contar a morte ao familiar que está sofrendo junto, e um conflito é não conseguir realizar algum procedimento que o familiar queira, pois não está ao meu alcance".

T3 - "Todos os dias temos desafios, a família às vezes inconformada com a situação pressionam a enfermagem, pedindo coisas que no momento já fica impossível devido o quadro do paciente".

$T 1$ - "Atendimento tardio, pouco caso, falta de atenção de alguns familiares, temos que cuidar com dignidade do começo ao fim, falta de material para atendermos melhor".

O processo de morte e morrer traz consigo a sensação de perda da identidade, angústia e isolamento. O paciente terminal necessita de apoio dos familiares e profissionais para vivenciar este processo. O cuidado humanizado da equipe associado ao fortalecimento dos laços familiares pode possibilitar meios para o seu enfrentamento de forma mais humana e sensível ${ }^{13}$.

Apesar da morte fazer parte do cotidiano dos profissionais, a equipe de enfermagem apresenta dificuldades para prestar cuidados ao paciente e interagir com seus familiares frente à possibilidade do óbito ${ }^{1}$. A presença dos profissionais de saúde é fundamental para o processo de morte dos pacientes terminais, em virtude da necessidade de apoio, atenção, vínculo e confiança mútua para o cuidado humanizado ${ }^{13}$.

Saber lidar com o processo de morte e morrer também foi citado pelos profissionais E2 e T2; ter compaixão (E1); atendimento tardio e falta de material (T1).

T2 - "Saber lidar com a situação, posicionar para dar conforto". 
E1 - "Mantenho o pensamento de que esta precisa ainda mais de minha atenção e disponibilidade, talvez meu maior desafio seja estabelecer a minha compaixão"

Os conflitos éticos que surgem na decisão de final da vida são delicados, sendo considerados um desafio para os profissionais da área da saúde, englobando tanto aspectos técnicos e éticos, para os profissionais, e emocionais para os familiares $^{22}$. A equipe de saúde deve estar preparada para dar más notícias, como a morte do paciente, em virtude da imprevisibilidade de reações do familiar ${ }^{23}$.

Presenciar a perda vivida pelo outro pode suscitar nas pessoas sentimentos de compaixão e solidariedade, inclusive a possibilidade de as próprias perdas serem lembradas e vivenciadas nesse enlutamento. Neste contexto, o contato com a família pode tornar-se grande fonte de sofrimento para o profissional da saúde $e^{23: 652}$.

O contato com o sofrimento do familiar que perde uma pessoa importante gera uma ansiedade que resulta em uma gama de atitudes. Em pesquisa de Tome; Popim; Dell'acqua ${ }^{23}$ encontraram dificuldades da equipe de enfermagem para oferecer o cuidado em virtude da identificação e comoção pelo sofrimento do familiar enlutado, bem como as próprias vivências de perdas o que gerou relações de empatia com a compreensão da dor gerada pela perda experimentada pelo outro. Desta forma processos reflexivos podem proporcionar a aproximação e proposição do cuidado requerido pela pessoa e sua família.

No momento da morte, é importante que o profissional reconheça sua impotência diante da morte. "Aqui, ele transforma a impotência em solidariedade humana, disponibilizando-se para atuar sobre todas as formas de sofrimento, transcendendo a técnica, sentindo e, de certa forma, sofrendo junto às dores da perda" 24:89.

\section{O enfrentamento dos desafios e conflitos relacionados ao cuidado à pessoa no processo de morte e morrer}

O enfrentamento da morte do paciente deve ser realizado num contexto natural, pois a morte faz parte da vida; sendo imprencindível o profissionalismo, a calma, a empatia, a paciência, a ética, a tolerância. 
E2 - "Temos que enfrentar naturalmente para poder resolver com mais facilidade este processo".

E1 - "Muitos se não padrão são os desafios e conflitos enfrentados, mas, sobretudo, a calma, a ética, o profissionalismo e a empatia são as palavras de ordem".

T1 - "Tento fazer o melhor, pois temos que cumprir regras, alguns conflitos têm que ter paciência, ética, essa é nossa profissão".

T2 - "Tolerar ao momento vivenciado, manter nível de profissionalismo".

T3 - "Procuro passar uma palavra de conforto e carinho, pois muitas vezes a pessoa fica lúcida poucos minutos antes de partir".

A vivência do processo de morte e morrer é um processo de aprendizagem do profissional de enfermagem; sendo que o cuidado é realizado fazendo tudo que for possível, apesar do processo de morte.

T4 - "Cada processo de morte morrer é um novo aprendizado para podermos enfrentar os outros que ainda estão por vir.".

T6 - "Tento explicar aos familiares que tudo que é possível está sendo feito".

Os conflitos éticos e bioéticos que envolvem a reanimação cardiovascular em cuidado paliativo foi delineado no relato do profissional T5: "É cada dia um desafio, pois é triste quando não há mais o que fazer com a doença, queremos reanimar o paciente, mas não podemos pois ele é paliativo"

O processo de morte e morrer é uma temática que gera controvésias na sociedade ${ }^{25}$. Em pesquisa de Cogo; Lunardi; Nietsche ${ }^{26}$ os conflitos na assistência ao paciente em fase terminal enfrentados pela equipe de enfermagem relacionaramse as incertezas e ambiguidades quanto às condutas de tratamento pela equipe multiprofissional, a fragilidade de interação entre os profissionais da saúde, as incertezas de diagnóstico e prognóstico do paciente e os riscos de punições legais diante da limitação de um esforço terapêutico, relacionado à ordem de não reanimar.

A ordem de não reanimar é uma determinação para a não realização do suporte avançado devida em caso de parada cardiorrespiratória do paciente que se 
encontra em fase final quando não mais se justificam tentativas de prolongamento da vida ${ }^{22}$. A Ordem de Não Reanimar encontra a legitimidade ética nos princípios da beneficência, não maleficência e no princípio da autonomia quando o paciente e família são envolvidos no processo de decisão ${ }^{25}$.

"A ONR deveria ser encarada como uma forma de diminuir o sofrimento da pessoa acometida e não como uma forma de induzir a morte"27:436.

O cuidado humanizado, a integralidade no cuidar, o cuidado solidário entre todos os integrantes da equipe de saúde a pacientes e familiares surge como um novo direcionamento ético ao cuidado terapêutico na qualidade de vida na morte ${ }^{27: 436}$.

Apesar de todas as reações emocionais que a morte acarreta, os profissionais de saúde têm o dever de permitir que o paciente tenha "uma morte digna, com o maior conforto possível e no seu tempo certo, sem pretender adiá-la ou atrasá-la indevidamente"25:478.

"É importante que tanto os profissionais quanto os familiares estejam atentos a esse dilema, criando diretrizes e discutindo a legitimidade da recusa do prolongamento da vida nos casos de morte iminente"22:43. A Ordem de Não Ressuscitar é prática digna, considerada no paliatismo como ortotanásia ${ }^{25}$.

\section{Proposta da equipe de Enfermagem para o enfrentamento dos desafios e conflitos vivenciados no processo morte e morrer, no intuito de melhorar o cuidado do profissional de enfermagem}

Todos os profissionais entrevistados sugeriram capacitação sobre tanatologia, palestras, reuniões, como forma de sensibilizar a equipe para o cuidado de enfermagem ético e humanizado no processo de morte e morrer, buscando a dignidade da finalização, dignidade de morrer sem dor, sem sofrimento e solidão.

A educação é entendida como desenvolvimento pessoal, aperfeiçoamento e cultivo do ser, que também pressupõe uma preparação para a morte, envolvendo "comunicação, relacionamentos, perdas, situações-limite, como, por exemplo: fases do desenvolvimento, perda de pessoas significativas, doenças, acidentes, até o confronto com a própria morte"16:485.

A partir da reflexão sobre tanatologia considera-se primordial a organização de espaços para discussão do tema morte entre os profissionais, para 
Artigo Original

Atenção à Saúde

dar subsídios ao enfrentamento das dificuldades e sofrimento neste processo e na comunicação de más notícias ${ }^{23}$. Educar para a morte é também preparar profissionais de saúde para lidar com ela ${ }^{16,19-20}$.

\section{CONSIDERAÇÕES FINAIS}

A equipe de enfermagem vivencia situações de pacientes em processo de morte-morrer frequentemente no seu trabalho. Os sentimentos da equipe de enfermagem frente ao processo de morte e morrer esta associada à tristeza, dor, consternação; apego; descanso para o sofrimento, sendo necessário o cuidado humanizado e a compaixão em relação ao paciente e família que vivencia este processo.

A morte é percebida pela equipe de enfermagem como um processo natural, que faz parte da vida, apesar do sofrimento, tristeza e muitas vezes o apego. O processo que envolve a morte e o morrer proporciona a equipe aprendizagem adquirida com a experiência e a troca de conhecimento com os profissionais, sendo necessário o cuidado do profissional para não envolver-se emocionalmente, buscando o equilíbrio emocional apoiado na espiritualidade.

A atuação da Equipe de Enfermagem frente à família e paciente durante o processo de Morte e Morrer deve ser embasada na solidariedade, empatia, apoio, carinho, dedicação, amor; com uma comunicação clara e respeitando os princípios éticos que norteiam o cuidado de enfermagem, além da assistência técnica, sendo essencial oferecer apoio e consolo aos familiares.

A família foi citada como um dos maiores desafios enfrentados pela equipe de enfermagem, seja estar diante da dor do familiar, as dificuldades inerentes à comunicação da má notícia; não poder realizar alguns procedimentos solicitados pelos familiares; falta de atenção de alguns familiares. Outros conflitos delineados na pesquisa relacionaram-se ao saber lidar com o processo de morte e morrer; atendimento tardio; falta de material e os conflitos éticos e bioéticos que envolvem a reanimação cardiovascular em cuidado paliativo.

A pesquisa demonstrou claramente as dificuldades inerentes ao cuidado de enfermagem no processo de morte e morrer, sendo que existe deficiência na formação dos profissionais que lidam com este processo; sendo necessária a formação dos profissionais de enfermagem na educação para a morte. 
Considera-se primordial a capacitação sobre tanatologia e a sensibilização da equipe para o cuidado de enfermagem humanizado do processo de morte e morrer; com a abertura de espaços para reflexão e discussão do tema morte entre os profissionais.

O surgimento de emoções como ansiedade, frustração, medo e falta de preparação para lidar com a morte pode estar relacionado com uma defasagem da educação para a morte na graduação, que não prepara esses profissionais para este tipo de rotina nos hospitais, que é conviver diariamente com o sofrimento dos outros. Por isso, sugere-se a estes profissionais que se capacitem para esta demanda, participando de cursos, realizando leituras, bem como conversando com colegas mais experientes, visando conhecer as melhores formas, do ponto de vista ético, bem como operacional, para poder lidar com estas questões no dia a dia de sua prática.

Além disso, considera-se que, no processo de assistência ao paciente em fase terminal a enfermagem deve ser presença contínua, conforto, carinho, atenção e cuidado impecável na dor, hidratação, higiene e conforto. A enfermagem deve ser presença atenta e sensível para garantir o processo de morte e morrer sem dor e sem sofrimento, com dignidade.

\section{REFERÊNCIAS}

1. Nunes FNL, Araújo KM, Silva LDC. As evidências sobre o impacto psicossocial de profissionais de enfermagem frente à morte. R. Interd. 2016 out/nov/dez; 9(4):16572.

2. Silva RS, Campos ERA, Pereira Á. Cuidando do paciente no processo de morte na Unidade de Terapia Intensiva. Rev. esc. enferm. USP, São Paulo, 2011 Jun.; 45(3):738-44.

3. Lima VR, Buys R. Educação para a morte na formação de profissionais de Saúde. Arquivos Bras. Psic. 2008;60(3):52-63.

4. Almeida AS, Barlem ELD, Tomaschewski-Barlem JG, Lunardi VL. Produção científica da enfermagem sobre morte/ morrer em unidades de terapia intensiva. Enferm. Foco, 2013;4(3,4):179-83. 


\section{Artigo Original \\ Atenção à Saúde}

5. Freitas TLL, Banazeski AC, Eisele A, Souza EM, Bitencourt JVOV, Souza SSF. O olhar da enfermagem diante do processo de morte e morrer de pacientes críticos: uma revisão integrativa. Enfermería Global 2016;15(1):322-60.

6. Bernieri J, Hirdes A. O preparo dos acadêmicos de enfermagem brasileiros para vivenciarem 0 processo morte-morrer. Texto contexto enferm. 2007 Mar; 16(1):89-96.

7. Leopardi MT. Metodologia da Pesquisa na Saúde. Florianópolis: UFSC, 2002. 294 p.

8. Minayo MCS. Pesquisa social: teoria, método e criatividade. 28 ed. Petrópolis, RJ: Vozes; 2016. 96 p.

9. Brasil. Conselho Nacional de Saúde. Resolução oo 510, de 07 de abril de 2016.[acesso em 2016 out. 20$]$ Disponível em: http://conselho.saude.gov.br/resolucoes/2016/Reso510.pdf.

10. Azeredo NSG, Rocha CF, Carvalho PRA. O enfrentamento da morte e do morrer na formação de acadêmicos de Medicina. Rev. bras. educ. med., Rio de Janeiro, 2011;35(1):37-43.

11. Tamada JKT, Dalaneze AS, Bonini LMM, Melo TRC. Relatos de médicos sobre a experiência do processo de morrer e a morte de seus pacientes. Rev. Med. São Paulo 2017 abr/jun; 96(2):81-7.

12. Mendes AM. A prática do enfermeiro com pacientes da UTI: uma abordagem psicodinâmica. Rev. Bras. Enfermagem, 2009; 49 (2):267-80.

13. Santana JCB, Pessini L, Sá AC. Vivências de profissionais da saúde frente ao cuidado de pacientes terminais. Enfer. Rev. 2017;20(1):1-12.

14. Fontoura EG. Sentido da vida: vivências dos cuidados de enfermeiros à pessoa no processo de morte e morrer, Salvador: UFB, 2013.

15. Hayasida NMA, Assayag RH, Figueira I, Matos MG. Morte e luto: competências dos profissionais. Revista Brasileira de Terapias Cognitivas, 2014;10(2):112-121.

16. Kovács MJ. Educação para a morte. Psicologia: Ciência e Profissão, 2005; 25(3):484-97.

17. Kübler - Ross, Elizabeth. Sobre a morte e o morrer. 8.ed. São Paulo: M. Fontes, 2017.

18. Oliveira PP, Amaral JG, Viegas SM F, Rodrigues AB. Percepção dos profissionais que atuam numa instituição de longa permanência para idosos sobre a morte e o morrer. Ciênc. Saúde coletiva, 2013 Set.; 18(9):2635-44. 
19. Kovács MJ (Coord). Morte e Existência Humana: Caminho de Cuidado e Possibilidades de Intervenção. RJ: Guanabara Koogan, 2008.

20. Kovács MJ. Desenvolvimento da tanatologia: Estudos sobre a morte e o morrer. Paidéia, 1008;18(41):457-68..

21. Kovács MJ. Instituições de saúde e a morte: Do interdito à comunicação. Rev. Psicologia Ciência e Profissão, 2011; 31(3):482-503.

22. Bandeira A, Cabral S, Panka M, Bonamigo E. Ordem de Não Reanimar em Países Latino-Americanos. Anais de Medicina, 20141(1):42-4.

23. Tome LY, Popim RC, Dell'acqua MCQ. Enfermagem cuidando de paciente adulto e família no processo de morte em sala de emergência. Cienc Cuid Saude, 2011; 10(4):650-57.

24. Ruiz EM, Gomes AMA. Apelo à humanização da morte nas práticas de saúde. In: Brasil. Ministério da Saúde. Secretaria de Atenção à Saúde. Departamento de Ações Programáticas e Estratégicas. Cadernos Humaniza SUS - Atenção hospitalar. Brasília: Ministério da Saúde, 2011. Cap. 6.

25. França D, Rego G, Nunes R. Ordem de não reanimar o doente terminal: dilemas éticos dos enfermeiros. Revista Bioética, 2010;18(2):469-81.

26. Cogo SB, Lunardi VL, Nietsche EA. Considerações acerca da atuação do enfermeiro na aplicabilidade das Diretivas Antecipadas de Vontade. Enferm. Foco 2017;8 (2):26-30.

27. Soratto MT, Silvestrini F. Dilemas éticos da equipe de enfermagem frente à ordem de não ressuscitar. Revista Bioethikos, Centro Universitário São Camilo, São Paulo, SP, 2010;4(4): 431-6. 